\title{
Effects of Surface Characteristics of AISI 304 Stainless Steel by Wet Shot Peening and its Wear and Corrosion Behavior
}

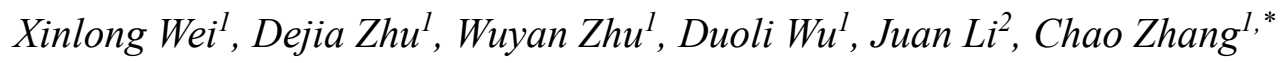 \\ ${ }^{1}$ School of Mechanical Engineering, Yangzhou University, Yangzhou 225127, China \\ ${ }^{2}$ School of Mechanical and Electrical Engineering, Nanjing Forestry University, Nanjing 210037 , \\ China \\ *E-mail: zhangc@yzu.edu.cn
}

doi: $10.20964 / 2020.06 .57$

Received: 3 February 2020 / Accepted: 30 March 2020 / Published: 10 May 2020

\begin{abstract}
In this paper, wet shot peening (WSP) is applied to investigate the influence on wear and corrosion behavior of AISI 304 stainless steel using dry reciprocating sliding wear tests and electrochemical impedance spectroscopy (EIS) experiments. Surface modifications including microstructure, surface roughness, microhardness and phase transformation are characterized. Results show that wet shot peening produces grain refinement because of intersection of deformation twins at different directions, increases surface roughness and generates martensite phase. Microhardness at the top surface can be enhanced significantly due to the strain hardening produced by WSP. Results of dry sliding wear tests reveal a remarkable improvement in wear resistance by WSP. The wear mechanism is a mixture of abrasive and adhesive wear for both as-received and wet shot peened AISI 304 stainless steel. Results of EIS experiments show that the charge transfer resistance of relative higher peening coverage WSP treated sample is higher than those of lower peening coverage WSP treated and as-received samples in the acid chloride solution at room temperature. The improved corrosion resistance for higher peening coverage WSP can be achieved by the positive combined action of grain refinement, surface roughness and deformation induced martensite.
\end{abstract}

Keywords: Wet shot peening, Corrosion resistance, Wear resistance, Electrochemical impedance spectroscopy, Microstructure, Deformation induced martensite

\section{$\underline{\text { FULL TEXT }}$}

(C) 2020 The Authors. Published by ESG (www.electrochemsci.org). This article is an open access article distributed under the terms and conditions of the Creative Commons Attribution license (http://creativecommons.org/licenses/by/4.0/). 